\title{
Carcinoma de Pequenas Células Hipercalcêmico do Ovário
}

\author{
Small Cell Carcinoma of the Ovary with Hypercalcemia
}

Gustavo Cardoso Guimarães, Pablo Roberto Novik, Andréa Paiva Gadêlha, Sueli Monterroso da Cruz Renata de Almeida Coudry, Fauzer Simão Abrão

\section{RESUMO}

Objetivos: apresentar três casos recentes de carcinoma de pequenas células hipercalcêmico $(\mathrm{CPCH})$ do ovário atendidos em nossa instituição quanto às suas características clínicas, diagnóstico e evolução pós-tratamento.

Métodos: foram obtidos dados dos prontuários médicos arquivados no Serviço de Arquivo Médico e Estatística (SAME) com respeito às características epidemiológicas, clínicas e evolução, além de dados histopatológicos obtidos no Serviço de Anatomia Patológica dos três pacientes com diagnóstico de carcinoma de pequenas células hipercalcêmico do ovário.

Resultados: as idades quando do diagnóstico foram de 26, 36 e 68 anos. O diâmetro tumoral variou de 8,8 a $23 \mathrm{~cm}$, com média de $14 \mathrm{~cm}$. Todas as pacientes apresentavam hipercalcemia, com cálcio total de 8,9, 10,8 e 16,7 mEq/dL (VN = 8,8 a 10,2) e cálcio iônico de 1,26, 1,27 e $1,21 \mathrm{mEq} / \mathrm{dL}(V N=1,12$ a 1,23), respectivamente. Todas as pacientes foram submetidas a cirurgia e esquemas de quimioterapia contendo platina. Duas pacientes que recebram quimioterapia adjuvante à cirurgia apresentam-se sem evidência de doença 2 e 18 meses depois. A outra paciente, que teve o diagnóstico inicial de tumor de células da granulosa, recebeu quimioterapia apenas após a recidiva e encontra-se viva com doença 32 meses após o diagnóstico.

Conclusão: dentre os indicadores prognósticos de maior importância encontramos: o estádio inicial da neoplasia, a idade, a presença de hipercalcemia, tamanho tumoral, presença de grandes células, tipo de cirurgia realizada e tempo para início do tratamento. O tratamento ideal para o carcinoma de pequenas células do tipo hipercalcêmico permanece desconhecido, devido a múltiplos fatores, como: estadiamento inadequado, múltiplas abordagens e esquemas terapêuticos empregados, dificuldade no diagnóstico histológico inicial e raridade de casos.

PALAVRAS-CHAVE: Carcinoma de pequenas células. Hipercalcemia. Ovário: câncer.

\section{Introdução}

O carcinoma de pequenas células hipercalcêmico $(\mathrm{CPCH})$ do ovário é uma entidade rara, descrita por Dickersin et al. ${ }^{1}$, e apresenta-se como tumor indiferenciado associado a hipercalcemia e com evolução clínica desfavorável. Os sinais e sintomas relacionados aos tumores deste tipo incluem cólicas abdominais, irregularidades mentruais, náuseas e vômitos e infertilidade. Os

Departamento de Ginecologia do Centro de Tratamento e Pesquisa Hospital do Cancer A. C. Camargo. São Paulo- SP. Correspondência:

Gustavo Cardoso Guimarães

Departamento de Cirurgia Pélvica

Rua Prof. Antônio Prudente 211 - Liberdade

01509-010 - São Paulo - SP

Tel. 55 (11) 3272-5100; Fax: 55 (11) 242-0500

e-mail: guimaraesgc@uol.com.br. sintomas associados a hipercalcemia incluem irritabilidade, hipertensão, fadiga, polaciúria, polidipsia, constipação, dores abdominal e lombar e insuficiência renal ${ }^{2}$.

O diagnóstico anatomopatológico pode ser dificil. Entretanto achados de tumor indiferenciado e hipercalcemia devem levantar suspeita de $\mathrm{CPCH}$.

O tratamento ideal ainda não está definido devido à raridade dos casos, dificuldades diagnósticas e estadiamento inadequado. Apesar disso, o tratamento adjuvante após cirurgia radical parace estar associado a melhores resultados.

\section{Pacientes e Métodos}

Foram obtidos dados dos prontuários médi- 
cos no Serviço de Arquivo Médico e Estatística (SAME), dos quais foram analisados: idade, estádios iniciais, tamanho do tumor, níveis de cálcio total e iônico séricos, tipo de cirurgia, esquemas de quimioterapia empregados e evolução.

Todos os casos foram revistos por um único patologista. Os achados histológicos geralmente revelam um padrão difuso de células pequenas dispostas em ninhos ou cordões, com citoplasma escasso. A variante de grandes células apresenta células com abundante citoplasma eosinofilico, núcleo central e nucléolos proeminentes. Em 60\% dos casos se observa a presença de glóbulos hialinos eosinofilicos intracitoplasmáticos ${ }^{2}$. Podem ser vistos em $10 \%$ dos casos glândulas mucosas ou mesmo células em anel de sinete. Numerosas figuras de mitose estão presentes em todos os casos, mas com uma grande variação entre eles².

\section{Resultados}

Na Tabela 1 observamos um resumo dos achados obtidos dos três casos avaliados, bem como a resposta ao tratamento. Os achados histopatológicos nestes três casos foram de padrão difuso de pequenas células que evidenciavam ninhos e cordões de células com núcleos ovalados ou arredondados, hipercromáticos, com nucléolos evidentes em alguns núcleos e com numerosas figuras de mitoses (Figuras 1 e 2).

Tabela 1 - Resumo dos achados clínicos e resultados do tratamento.

\begin{tabular}{|c|c|c|c|c|c|c|}
\hline Paciente & Idade & $\begin{array}{l}\text { Diâmetro tumoral } \\
\qquad(\mathrm{cm})\end{array}$ & $\begin{array}{l}\text { Cálcio total } \\
(\mathrm{mEq} / \mathrm{mL})\end{array}$ & $\begin{array}{l}\text { Cálcio ionico } \\
(\mathrm{mEq} / \mathrm{mL})\end{array}$ & Esquema de QT inicial & Estado atual \\
\hline 1 & 26 & 10 & 16,7 & 1,21 & $\begin{array}{l}6 \text { ciclo de ifosfamida }\left(1,5 \mathrm{~g} / \mathrm{m}^{2}\right) \text { D1 } \\
\text { a D4 + cisplatina }\left(100 \mathrm{mg} / \mathrm{m}^{2}\right) \text { D1. }\end{array}$ & $\begin{array}{l}\text { Viva com câncer há } 32 \\
\text { meses. }\end{array}$ \\
\hline 2 & 36 & 23 & 10,8 & 1,27 & $\begin{array}{l}4 \text { ciclos de cisplatina }\left(20 \mathrm{mg} / \mathrm{m}^{2}\right) \\
\text { D1 a D5 + etoposida }\left(100 \mathrm{mg} / \mathrm{m}^{2}\right)\end{array}$ & $\begin{array}{l}\text { Sem evidência de doença, } \\
18 \text { meses após QT. }\end{array}$ \\
\hline 3 & 68 & 8,8 & 8,9 & 1,26 & $\begin{array}{l}6 \text { ciclos de carboplatina (AUC 6) } \\
+ \text { etoposida }\left(120 \mathrm{mg} / \mathrm{m}^{2}\right) \mathrm{D} 1\end{array}$ & $\begin{array}{l}\text { Sem evidência de doença, } \\
2 \text { meses após QT. }\end{array}$ \\
\hline
\end{tabular}

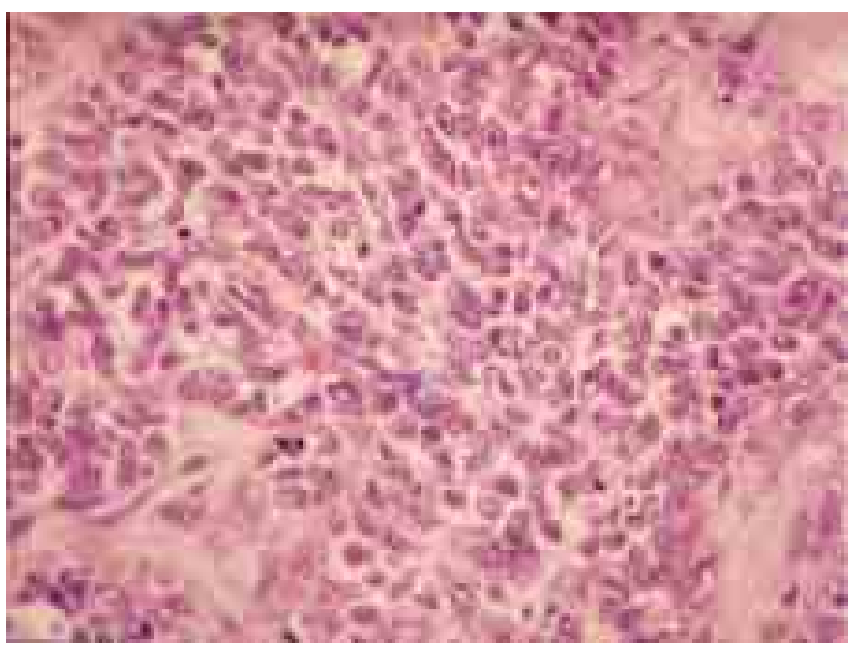

Figura 1 - Neoplasia contituída por células pequenas arranjadas em padrão difuso. Coloração HE, X500.

Estruturas foliculares revestidas por células tumorais contendo material eosinofilico estavam presentes em dois casos descritos (Figura 2). Em um dos casos observava-se um estroma fibroso denso mais evidente. Nos demais, apenas es-

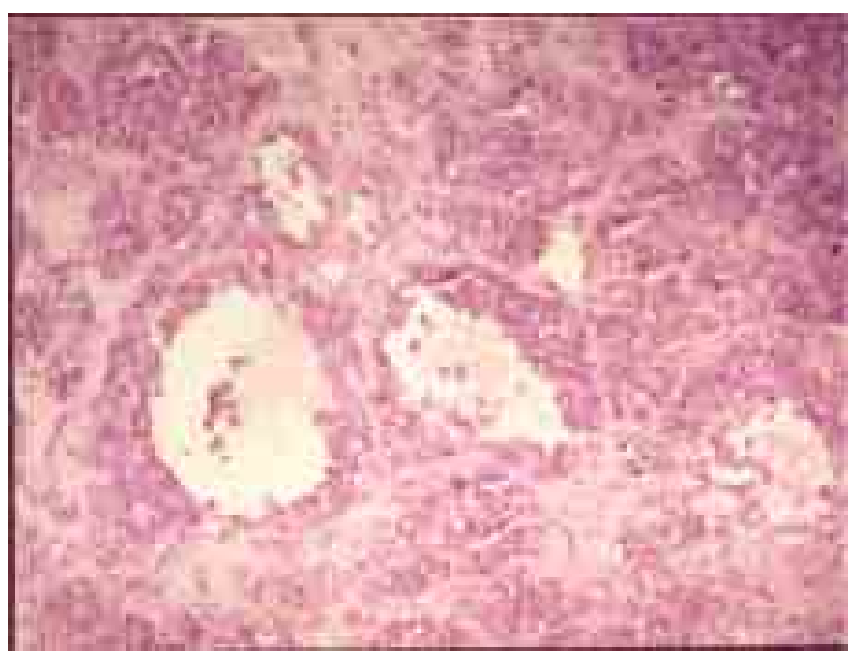

Figura 2 - Presença de ninhos de células pequenas e folículos delineados por células com citoplasma escasso e contendo material eosinofílico. Coloração HE, X125.

casso estroma fibroso envolvendo alguns agrupamentos de células tumorais. Os casos são relatados a seguir.

Caso 1: RWLS, 26 anos, branca, nuligesta, com queixa de dismenorréia há um ano e dor aguda 
há quinze dias. Apresentava à ultra-sonografia (USG) tumoração sólida de $10 \mathrm{~cm}$ de diâmetro no ovário direito. As dosagens de $\alpha$-fetoproteína e $\beta$ HCG no plasma foram negativas. Foi submetida a cirurgia laparoscópica no nosso serviço, com cirurgia conservadora do ovário (devido à idade e desejo reprodutivo da paciente), lavado peritoneal e linfadenectomia iliaca direita. O diagnóstico anatomopatológico foi de tumor de células da granulosa tipo juvenil em estádio Ic. Não recebeu terapêtica adjuvante.

Após 10 meses apresentou dor abdominal e a tomografia (TC) pélvica demonstrou volumosa tumoração com compressão de ureter, bexiga e reto. A revisão das lâminas da peça cirúrgica evidenciou carcinoma indiferenciado, compativel com tumor de pequenas células. O cálcio sérico foi de $16,7 \mathrm{mEq} / \mathrm{mL}(\mathrm{VN}=8,8$ a 10,2$)$ e cálcio iônico de $1,21 \mathrm{mEq} / \mathrm{mL}(\mathrm{VN}=1,12$ a 1,23$)$. Foi submetida a laparotomia e a biópsia confirmou o diagnóstico de carcinoma de pequenas células hipercalcêmico, cuja citorredução não foi exeqüivel.

Foi então tratada com 6 ciclos de ifosfamida $\left(1,5 \mathrm{~g} / \mathrm{m}^{2} \mathrm{D} 1 \mathrm{a} \mathrm{D} 4\right)$ e cisplatina $\left(100 \mathrm{mg} / \mathrm{m}^{2} \mathrm{D} 1\right)$, com normalização dos níveis de cálcio. Ao término da quimioterapia (QT), foi submetida a cirurgia para second look, durante a qual se realizou histerectomia total abdominal, salpingo-ooforectomia, omentectomia, linfadenectomia seletiva pélvica e para-aortica e biópsias múltiplas. Havia presença de tumor apenas no septo reto-vaginal. Evoluiu com nova recidiva seis meses depois, sendo submetida a nova quimioterapia com três ciclos de PEB (bleomicina, etoposida e cisplatina), havendo progressão da doença abdominal. Recebeu então dois ciclos com Taxol, com progressão da doença no mediastino. Encontra-se viva com doença em atividade há 32 meses.

Caso 2: ALM, 36 anos, branca, nuligesta, procurou outro serviço com queixa de dor abdominal com 15 dias de duração sem relação com a menstruação. À USG, observava-se massa anexial heterogênea com 23,8 cm de diâmetro. Foi submetida a exérese da tumoração, com diagnóstico histopatológico de adenocarcinoma seroso papilífero do ovário. Encaminhada ao nosso serviço, a revisão de lâmina revelou carcinoma pouco diferenciado com aspectos morfológicos sugestivos de carcinoma de pequenas células hipercalcêmico. Os niveis de cálcio sérico eram de 10,8 $\mathrm{mEq} / \mathrm{mL}$, o de cálcio iônico de $1,27 \mathrm{mEq} / \mathrm{mL}, \mathrm{CEA}$ de 1,3 mUI/mL, Ca $72-4$ de 0,8 mUI/mL, e Ca-125 de $68 \mathrm{mUI} / \mathrm{mL}$. Submetida a laparotomia com histerectomia total abdominal, salpingoooforectomia, omentectomia, lavado peritoneal, linfadenectomia seletiva pélvica e para-áortica. $\mathrm{O}$ estádio B foi IIIb.
Recebeu QT adjuvante com 4 ciclos de PEB (bleomicina $30 \mathrm{mg} / \mathrm{m}^{2}$ no D2, D9, D16, etoposida, $100 \mathrm{mg} / \mathrm{m}^{2} \mathrm{D} 1 \mathrm{a} \mathrm{D} 5$, e cisplatina $20 \mathrm{mg} / \mathrm{m}^{2} \mathrm{D} 1 \mathrm{a}$ D5, evoluindo com queda dos níveis de cálcio e sem sinais de doença 18 meses após o término da quimioterapia.

Caso 3: LABV, 68 anos, branca, em menopausa há 26 anos, tercigesta, secundipara, com um abortamento, procurou outro serviço por aumento abdominal e dor lombar esquerda. Apresentava tumoração anexial esquerda complexa de 8,8 $\mathrm{cm}$ de diâmetro ao USG. Foi submetida a cirurgia com diagnóstico anatomopatológico de adenocarcinoma seroso papilifero do ovário. Os exames préoperatórios mostraram: CEA 0,9 mUI/mL, Ca 125 de $173 \mathrm{mUI} / \mathrm{mL}$, cálcio sérico $8,9 \mathrm{mEq} / \mathrm{mL}$ e cálcio iônico de 1,26 mEq/mL. Realizada cirurgia em nosso serviço, sendo estadiada como IIIc. O diagnóstico anatomopatológico foi de tumor indiferenciado sugestivo de carcinoma de pequenas células. No pós-operatório apresentava cálcio sérico de 9,4 mEq/mL e o cálcio iônico de $1,34 \mathrm{mEq} / \mathrm{mL}$. Tratada com quimioterapia adjuvante com seis ciclos de etoposida $120 \mathrm{mg} / \mathrm{m}^{2}$ D1 e carboplatina (AUC 6) e encontra-se sem sinais de doença 2 meses após o término da QT.

\section{Discussão}

O carcinoma de pequenas células do ovário pode se apresentar sob duas formas: uma do tipo pulmonar, não relacionado à idade e que tem características idênticas às de pequenas células do pulmão, e outro com características clínicas e patológicas distintas, que foi descrita por Dickersin et al. ${ }^{1}$.

Entre as características predominantes destacam-se o fato de acometer preferencialmente mulheres jovens e a ocorrência de duas apresentações clinicas distintas. A forma hipercalcêmica apresenta alto grau de malignidade e taxa de sobrevida em 5 anos inferior a $10 \%$. A sintomatologia em geral é semelhante a qualquer neoplasia ovariana e os sintomas de hipercalcemia só raramente são a causa do diagnóstico.

O carcinoma de pequenas células está relacionado à hipercalcemia em $60 \%$ dos casos. Outros tumores capazes de causar hipercalcemia são: carcinomas de células claras (em aproximadamente $18 \%$ dos casos), carcinoma seroso, carcinoma espinocelular derivado de cisto dermóide e disgerminoma (em $6 \%$ de cada), além de outros com menor freqüência ${ }^{2}$.

A extensão pélvica contígua ao ovário é freqüente e pode ser encontrada em metade dos ca- 
sos à apresentação ${ }^{2}$. Os achados histológicos geralmente revelam um padrão difuso de células pequenas dispostas em ninhos ou cordões com citoplasma escasso. Em 80\% dos casos observamse espaços foliculares preenchidos por material eosinofilico, podendo também apresentar células com abundante citoplasma eosinofílico, núcleo central e nucléolos proeminentes e, neste caso, são denominados variante de grandes células.

Young et al. ${ }^{2}$ chamam a atenção para a presença de grandes células em $50 \%$ dos casos e que em $12 \%$ o tumor pode ser exclusivamente composto destas. Em $60 \%$ dos casos se observa a presença de glóbulos hialinos eosinofilicos intracitoplasmáticos. Podem ser vistas em $10 \%$ dos casos glândulas mucosas ou mesmo células em anel de sinete. Numerosas figuras de mitose estão presentes em todos os casos, mas com uma grande variação entre eles ${ }^{2}$. As células se coram variavelmente para vimentina, citoqueratinas e antígeno epitelial de membrana.

Para todas as pacientes foi efetuada revisão de lâminas, com diagnóstico de carcinoma pouco diferenciado com imuno-histoquímica positiva para citoqueratina, antígeno epitelial de membrana e vimentina, e negativa para $\alpha$-inibina, o que fez o diagnóstico diferencial com tumor das células da granulosa. Os três casos descritos são de padrão difuso de pequenas células que evidenciam ninhos e cordões de células com núcleos ovalados ou arredondados, hipercromáticos, com nucléolos evidentes em alguns núcleos e com numerosas figuras de mitoses. Estruturas foliculares revestidas por células tumorais contendo material eosinofilico estavam presentes em dois casos descritos. Em um dos casos observavam-se um estroma fibroso denso mais evidente. Nos demais apenas escasso estroma fibroso envolvendo alguns agrupamentos de células tumorais. Todos estes apresentavam no entanto características clínicas, histológicas e imunohistoquímicas que permitiam separá-los de carcinoma hipercalcêmico de pequenas células primário do ovário.

Dentre os indicadores prognósticos de maior importância encontramos: o estádio inicial da neoplasia, com 33\% de sobrevida para o estádio clínico (EC) Ia , contra $10 \%$ para Ic e $6,5 \%$ para EC II e III; a idade inferior a 30 anos; a presença de hipercalcemia, além do tamanho tumoral (tumores com diâmetro maior que $10 \mathrm{~cm}$ ) e da presença de grandes células, que se mostraram como fatores prognósticos adversos para recorrência ${ }^{2}$. Há uma tendência a considerar o tipo de cirurgia realizada, já que cirurgia alargada para o EC Ia está associada a menor índice de recidiva $(23 \% \text { x 57\% })^{2}$.

$\mathrm{Na}$ série de Young et $\mathrm{al}^{2}$ pacientes que re- ceberam algum tipo de terapia adjuvante mostraram uma menor tendência a recorrência. Já a aneuploidia não tem se mostrado como fator prognóstico importante ${ }^{3}$.

Existem dúvidas quanto à origem destes tumores. Alguns autores sugerem uma diferenciação epitelial devido à presença de uma fina lâmina basal e numerosos desmossomos na microscopia eletrônica ${ }^{4,5}$, ao passo que outros propõem uma origem germinativa pelas características clinicas, histológicas e imuno-histoquímicas, como a coexpressão de vimentina e de citoqueratinas, além de positividade para $\alpha-1$ antitripsina ${ }^{6}$.

O diagnóstico diferencial da variante de grandes células é feito principalmente com os tumores da célula da granulosa, em razão de estruturas pseudofoliculares presentes em 20\% dos casos de carcinomas de pequenas células e a ausência de corpos de Call-Exner, além da forte atividade mitótica e da dosagem hormonal (hipercalcemia ou hiperestrogenismo, que permite a diferenciação diagnóstica). Outros diagnósticos diferenciais incluem: carcinoma embrionário, tumor do saco vitelínico e disgerminoma, que acometem a mesma faixa etária, mas apresentam células tumorais claras e citoplasma rico em glicogênio, e metástase de melanoma maligno (células HMB-45 e proteína S100) e dos tumores rabdóides, cuja histologia e perfil imunohistoquímico são semelhantes mas podem ser diferenciados pela presença de pequenas células e hipercalcemia ${ }^{2}$.

Outros diagnósticos diferenciais possiveis são: tumores de pequenas células tipo pulmonar, primário ou metastático para o ovário ${ }^{7}$, linfomas, rabdomiossarcoma alveolar, tumor neuroectodérmico primitivo e neuroblastoma.

O mecanismo fisiopatológico da hipercalcemia não foi esclarecido, apesar de intensa investigação sobre o assunto. Burton et al. ${ }^{8}$ e MathiasGuiu et al. ${ }^{9}$ descreveram a ação da proteína relacionada ao paratormônio (PTH-rP) que é um peptídio de $16 \mathrm{kDa}$ cujo gene está situado no cromossomo 12. É produzido pelas células tumorais e apresenta efeito similar ao do paratormônio, mas não foi comprovada a relação entre positividade para PTH-rP e o nível da hipercalcemia pré-operatória.

Raros relatos de casos familiares indicam a possibilidade de predisposição genética neste tipo especial de tumor ${ }^{2,6,10}$.

O tratamento ideal para o carcinoma de pequenas células do tipo hipercalcêmico permanece desconhecido, devido a múltiplos fatores como estadiamento inadequado, múltiplas abordagens e esquemas terapêuticos empregados, dificuldade no diagnóstico inicial e raridade de casos. 


\section{SUMMARY}

Purpose: to evaluate clinical findings, diagnosis and prognosis of three recent hypercalcemic small cell ovarian carcinoma (HSCC) cases treated in our institution.

Methods: information concerning epidemiological data and clinical evolution was obtained from the medical record review. Diagnosis was confirmed through histologic evaluation by our Pathology Department.

Results: patients were, at diagnosis, 26, 36 and 38 years old. Tumor diameter ranged from $8.8 \mathrm{~cm}$ to $23 \mathrm{~cm}$ (mean $=14 \mathrm{~cm}$ ). All patients presented hypercalcemia with total calcium serum levels of $8.9,10.8$ and $16.7 \mathrm{mEq} / \mathrm{dL}(\mathrm{NV}=8.8$ to 10.2) and ionic calcium levels of 1.26, 1.27 and $1.21 \mathrm{mEq} / \mathrm{dL}$ respectively ( $N V=1.12$ to 1.23$)$. All three patients were submitted to surgical treatment and chemotherapy with platinum-based regimens. In two patients the chemotherapy was adjuvant to the primary surgical treatment. Both are alive and disease-free after 2 and 18 months of follow-up. The other patient had initially the diagnosis of granulosa cell tumor, receiving chemotherapy only after tumor recurrence. Now she is alive with tumor 32 months after diagnosis.

Conclusion: the main prognostic factors, in the literature and our experience, are the tumor stage at diagnosis, patient's age, presence of hypercalcemia, large cells, tumor diameter, type of surgical treatment and delay of definitive therapy. The ideal treatment of the hypercalcemic small cell ovarian carcinoma remains unknown. Difficulties in determining a standard therapeutic strategy include rarity of the neoplasm, frequently inadequate initial staging, difficulties in histologic diagnosis and multiple therapeutic approaches.

KEY WORDS: Small cell carcinoma. Ovarian neoplasm. Hypercalcemia.

\section{Referências}

1. Dickersin GR, Kline IW, Scully RE. Small cell carcinoma of the ovary with hypercalcemia: a report of eleven cases. Cancer 1982; 49:188-97.

2. Young RH, Oliva E, Scully RE. Small cell carcinoma of the ovary, hypercalcemic type. A clinicopathological analysis of 150 cases. Am J Surg Pathol 1994; 18:1102-16.

3. Eichhorn JH, Bell DA, Young RH, et al. DNA content and proliferative activity in ovarian small cell carcinomas of the hypercalcemic type. Implications for diagnosis, prognosis, and histogenesis. Am J Clin Pathol 1992; 98:579-86.

4. Abeler V, Kjorstad KE, Nesland JM. Small cell carcinoma of the ovary. A report of six cases. Int J Gynecol Pathol 1988; 7: 315-29.

5. McMahon JT, Hart WR. Ultrastructural analysis of small cell carcinomas of the ovary. Am J Clin Pathol 1988; 90:523-9.

6. Ulbright TM, Roth LM, Stehman FB, Talerman A, Senekjian EK. Poorly differentiated (small cell) carcinoma of the ovary in young women: evidence supporting a germ cell origin. Hum Pathol 1987; 18:175-84.

7. Eichhorn JH, Young RH, Scully RE. Nonpulmonary small cell carcinoma of extragenital origin metastatic to the ovary. Cancer 1993; 71:17786.

8. Burton PB, Knight DE, Quirke P, Smith R, Moniz C. Parathyroid hormone related peptide in ovarian carcinoma. J Clin Pathol 1990; 43:784.

9. Mathias-Guiu X, Prat J, Young RH, et al. Human parathyroid hormone-related protein in ovarian small cell carcinoma: an immunohistochemical study. Cancer 1994; 73:1878-81.

10.Longy M, Toulouse C, Mage P, Chauvergne J, Trojani M. Familial cluster of ovarian small cell carcinoma: a new Mendelian entity? J Med Genet 1996; 33:333-5. 